\title{
Bioelectrochemical Detoxification of Phenolic Compounds during Enzymatic Pre-Treatment of Rice Straw
}

\author{
Sanath Kondaveeti, Raviteja Pagolu, Sanjay K. S. Patel, Ashok Kumar, Aarti Bisht, Devashish Das, \\ Vipin Chandra Kalia, In-Won Kim*, and Jung-Kul Lee*
}

Department of Chemical Engineering, Konkuk University, Seoul 05029, Republic of Korea

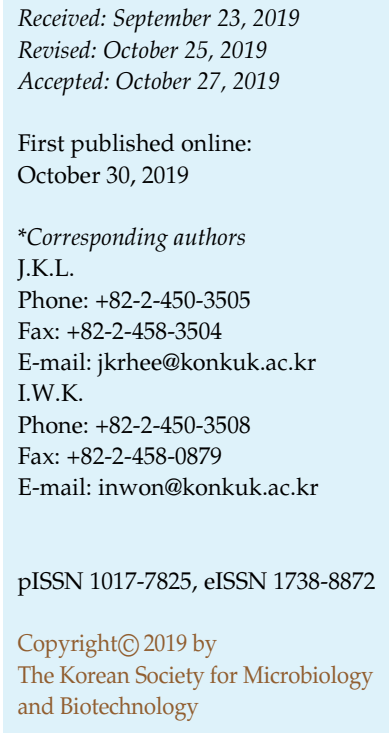

The use of lignocellulosic biomass such as rice straw can help subsidize the cost of producing value-added chemicals. However, inhibitory compounds, such as phenolics, produced during the pre-treatment of biomass, hamper the saccharification process. Laccase and electrochemical stimuli are both well known to reduce phenolic compounds. Therefore, in this study, we implemented a bioelectrochemical detoxification system (BEDS), a consolidated electrochemical and enzymatic process involving laccase, to enhance the detoxification of phenolics, and thus achieve a higher saccharification efficiency. Saccharification of pretreated rice straw using BEDS at $1.5 \mathrm{~V}$ showed $90 \%$ phenolic reduction $\left(\mathrm{Ph}_{\mathrm{r}}\right)$, thereby resulting in a maximum saccharification yield of $85 \%$. In addition, the specific power consumption when using BEDS $\left(2.2 \mathrm{~W} / \mathrm{Kg} \mathrm{Ph}_{\mathrm{r}}\right.$ ) was noted to be $24 \%$ lower than by the electrochemical process alone $(2.89 \mathrm{~W} / \mathrm{kg} \mathrm{Ph})$. To the best of our knowledge, this is the first study to implement BEDS for reduction of phenolic compounds in pretreated biomass.

Keywords: Voltage supplementation, bioelectrochemical detoxification, phenolic compounds, rice straw, hydrolysis

\section{Introduction}

Increasing concerns about global warming and depletion of fossil fuels have escalated research in biorefining as an alternative approach [1-4]. In this regard, lignocellulosic biomass material, such as rice straw, has been noted as a likely feedstock for generating biochemicals and biofuels. Moreover, rice straw is abundant in nature, and it bypasses the food-fuel debate [5].

In general, obtaining fermentable sugars, such as glucose from lignocellulosic materials, requires a pre-treatment, followed by detoxification and saccharification. However, the presence of inhibitory substances, such as phenolic compounds, furans, and weak acids can hamper the activity of the enzyme used for the generation of reducible sugars [6,7]. Among all the inhibitory compounds, phenolic compounds are viewed as highly detrimental to saccharification enzymes, including cellulase, even at low concentrations [8]. Since most cellulases are susceptible to phenolic inhibition, it is crucial to detoxify rice straw from the phenolic compounds [9]. To date, many researchers have attempted different detoxification methods, such as evaporation, solvent extraction, adsorption, ion exchange, and over liming [10, 11]. However, there are several limitations with these detoxification processes, including elevated operational and production costs, low efficiency of phenolic compound removal, and the possibility of removing the fermentable sugars alongside the phenolic compounds, ultimately leading to a low sugar yield. Additionally, formation of toxic byproducts [e.g., gypsum from $\left.\mathrm{Ca}(\mathrm{OH})_{2}\right]$ during detoxification can impede the enzymatic activity [12]. In this regard, biological detoxification by means of microbes and their enzymes, such as laccase, seems beneficial as a minimal amount of waste is generated [13].

Therefore, here we developed and characterized a bioelectrochemical detoxification system (BEDS) for the removal of the phenolic compounds in rice straw hydrolysate. The performance of BEDS in phenolic reduction was evaluated at different applied voltages with or without 
laccase as the biocatalyst. Laccase was chosen as the biocatalyst because of its ability to oxidize a wide range of phenolic compounds with simultaneous reduction of oxygen to water [14]. Moreover, laccase is extensively available in nature, where it can be found in higher plants, bacteria, insects, and fungi $[15,16]$. Principally, in the presence of oxidative environmental conditions, phenolic compounds are converted to radicals and then removed/ polymerized by radical polymerization [17, 18]. Likewise, we presumed that phenolic compounds generated from lignin depolymerization could be converted to radicals via application of different oxidative potentials by varying the external voltage, and the generated phenolic radicals could then be removed as polymeric compounds. Along with the detoxification process, deactivation of cellulase by various phenolic compounds alone or in combination was evaluated.

The main objective of pursuing BEDS in this study was to enhance the detoxification of phenolic compounds in pretreated biomass in comparison with the use of laccase alone. BEDS exhibited $90 \%$ phenolic reduction $\left(\mathrm{Ph}_{\mathrm{r}}\right)$ in rice straw hydrolysate without any loss of reducing sugars. Furthermore, the reducing sugar yield (85\%) from the saccharification process was higher in detoxified than in undetoxified rice straw hydrolysate. Therefore, BEDS can be an efficient system for removal of phenolic compounds, and it provides a feasible approach in field applications for production of biofuels and biochemicals from rice straw hydrolysate.

\section{Materials and Methods}

\section{Materials and Chemicals}

All the phenolic compounds [ferulic acid (99\%), gallic acid (98\%), vanillic acid (98\%), p-coumaric acid (98\%), and syringaldehyde $(99 \%)]$ used in the present study were procured from Sigma-Aldrich (USA). The commercial cellulase celluclast $1.5 \mathrm{~L}$ and $\beta$-glucosidase (BGL) from Aspergillus niger were used for saccharification. Laccase from Trametes versicolor was purchased from SigmaAldrich and used as the biocatalyst for the oxidation of phenols. All the other chemicals and reagents were purchased from various commercial sources and were used without any further purification.

\section{Enzymatic Assay}

The laccase activity was spectrophotometrically evaluated using ABTS as the substrate at room temperature. The activity of celluclast $1.5 \mathrm{~L}$ was evaluated and expressed in Filter Paper activity Units (FPUs). Laccase, BGL, and celluclast enzyme activities were measured as previously described [19]. One FPU is defined as the amount of enzyme that releases $1 \mu \mathrm{mol}$ of glucose-equivalents from hydrolysis of Whatman No. 1 filter paper per min. Protein concentration was assessed using the Bradford method (Bradford, 1976) with bovine serum albumin as the standard [20]. All the experimental analyses were individually performed in triplicate to maintain consistency.

\section{Front-End Processing of Rice Straw}

The rice straw (Oryza sativa L.) used in the present study was procured from Phygen Co., Ltd. (Korea) and was dried at $60^{\circ} \mathrm{C}$ for $24 \mathrm{~h}$. The dried rice straw was diced and milled using the laboratory hammer mill. The milled rice straw was sieved to remove any particles longer than $15 \mathrm{~mm}$ and shorter than $6 \mathrm{~mm}$. The final length of the rice straw particles was $2-6 \mathrm{~mm}$. The composition of the rice straw was $35.8 \%$ cellulose, $25.8 \%$ hemicellulose, $15.8 \%$ lignin, $9.3 \%$ ash, $8 \%$ protein, and $6 \%$ extractives on the basis of dry weight [21].

The milled rice straw ( $25 \mathrm{~g}$ by dry weight) was mixed with an appropriate amount of sulfuric acid $(0.5 \%)$ and tap water. The mix was then placed in a steam explosion reactor and incubated at $121^{\circ} \mathrm{C}$ for $60 \mathrm{~min}$. This pre-treated rice straw was filtered and washed with distilled water until its $\mathrm{pH}$ was neutralized [19]. Next, it was incubated in an oven at $60^{\circ} \mathrm{C}$ until it completely dried up, as assessed by its weight not decreasing any further, and then used in the experiments.

\section{Enzyme Deactivation Assay}

Inhibition of the cellulolytic enzymes Celluclast 1.5 L and BGL by phenolic compounds was studied during their hydrolysis of pretreated rice straw. For enzyme deactivation, the reaction mixture contained various types of individual phenolic compounds $(2 \mathrm{~g} / \mathrm{l})$, mixture of phenolic compounds $(2 \mathrm{~g} / \mathrm{l}), 20 \mathrm{mM}$ of each substrate (carboxymethyl cellulose and $p$-nitrophenyl- $\beta$-D-cellobioside), and 15 FPU of celluclast enzyme along with antibiotics [tetracycline $(40 \mu \mathrm{g} / \mathrm{ml})$ and cycloheximide $(30 \mu \mathrm{g} / \mathrm{ml})]$ against microbial contamination $[9,22]$. The mixture was then placed on a shaking incubator at $150 \mathrm{rpm}$ and $30^{\circ} \mathrm{C}$. To analyze the activity of the enzymes (EG, $\mathrm{CBH}$, and BGL), samples were taken every $3 \mathrm{~h}$ until the end of the digestion $(9 \mathrm{~h})$. The EG activity was assessed by measuring the amount of sugar (glucose) released from the substrate (carboxymethyl cellulose) using the Somogyi-Nelson analysis and glucose as the standard. Similarly, the CBH activity was assessed by using $p$-nitrophenyl- $\beta$-D-cellobioside ( $p$-NPC, Sigma-Aldrich) as the substrate under the conditions previously described $[23,24]$. Hydrolysis of $p$-NPC was defined as the amount of enzyme needed for the release of $1 \mu \mathrm{mol}$ of $p$-nitrophenol per minute. The activity of BGL was assessed by using $p$-nitrophenyl$\beta$-D-glucopyranoside as previously described [25].

\section{Detoxification of Pre-Treated Rice Straw Using Laccase}

The detoxification of pretreated rice straw was carried out in a 100-ml Erlenmeyer flask with $50 \mathrm{ml}$ of $50-\mathrm{mM}$ acetate buffer $(\mathrm{pH}$ $4.5)$. The reaction mixture consisted of laccase $(10 \mathrm{U} / \mathrm{ml}), 3 \mathrm{~g}$ of pretreated biomass, and antibiotics [tetracycline $(40 \mu \mathrm{g} / \mathrm{ml})$ and cycloheximide $(30 \mu \mathrm{g} / \mathrm{ml})]$. Samples were collected every $30 \mathrm{~min}$ 
until the end of the reaction $(2 \mathrm{~h})$ and centrifuged at 5,000 $\times g$ to collect the supernatants used for the assessment of phenolic degradation. The $\mathrm{Ph}_{\mathrm{r}}$ was analyzed as follows: Supernatant $(200 \mu \mathrm{l})$ of a laccase-detoxified sample was combined with distilled water $(800 \mu \mathrm{l})$, followed by the addition of Folin-Ciocalteau reagent $\left(500 \mu \mathrm{l}\right.$ ). After $3 \mathrm{~min}, \mathrm{Na}_{2} \mathrm{CO}_{3}$ (sodium carbonate, $2.5 \mathrm{ml}, 20 \% \mathrm{~W} / \mathrm{V}$ ) was added and the samples were left in the dark for $30 \mathrm{~min}$, after which their absorbance was measured at $725 \mathrm{~nm}$ using a UV-Vis spectrometer [26]. The concentrations of the phenolics were expressed as gram amount of catechol-equivalents per liter of the liquid phase.

\section{Bioelectrochemical Detoxification of Pre-Treated Rice Straw}

The bioelectrochemical detoxification with the application of external voltage $(0.5,1.0$, and $1.5 \mathrm{~V})$ was carried out in chronoamperometric mode with a biologic potentiostat (SP-150) in a single-chamber cell (Fig. 1). The total and working volumes of the cell were maintained at $100 \mathrm{ml}$ and $50 \mathrm{ml}$, respectively. Carbon cloth $\left(4 \mathrm{~cm}^{2}\right.$, Fuelcell Store Inc., USA) and platinum wire (Neoscience, Korea) were used as the working and counter electrode, respectively. $\mathrm{Ag} / \mathrm{AgCl}$ served as a reference electrode and was placed in close proximity to the working electrode. The bioelectrochemical detoxification reaction mixture consisted of acetate buffer ( $\mathrm{pH} 4.5,50 \mathrm{mM})$, laccase $(10 \mathrm{U} / \mathrm{ml}), \mathrm{NaCl}(0.1 \mathrm{M})$, $3 \mathrm{~g}$ of pretreated biomass, and antibiotics [tetracycline $(40 \mu \mathrm{g} / \mathrm{ml})$ and cycloheximide $(30 \mu \mathrm{g} / \mathrm{ml})]$. For the control, the same bioelectrochemical detoxification procedure was performed without laccase. Samples were collected every $30 \mathrm{~min}$ until the end of the reaction $(2 \mathrm{~h})$ and centrifuged $(5,000 \times g)$ to collect the supernatants used for the assessment of phenolic compound degradation. Concentrations of the phenolic compounds were determined as described in section 2.4. All the experiments were performed in each individual system of electrochemical, enzymatic (laccase), and BEDS, with replications $(n=3)$. The faradaic efficiency (FE) of BEDS and electrochemical system was determined using the following equation: $\mathrm{FE}=\mathrm{C}_{R} / \mathrm{C}_{\mathrm{I}} \times 100(\%)$, where $C_{R}$ is the total number of coulombs for reduced phenol and $C_{I}$ is the total number of coulombs of current applied to system.

\section{Saccharification of Pre-Treated and Detoxified Rice Straw}

Saccharification of pretreated and detoxified rice straw was pursued in a $100-\mathrm{ml}$ flask using cellulase. The reaction mixture consisted of detoxified biomass ( $0.4 \mathrm{~g})$, cellulase (15 FPU), BGL $(15 \mathrm{IU} / \mathrm{g})$, laccase $(10 \mathrm{U} / \mathrm{ml})$, tween $80(0.2 \%)$, and antibiotics [tetracycline $(40 \mu \mathrm{g} / \mathrm{ml})$ and cycloheximide $(30 \mu \mathrm{g} / \mathrm{ml})$ ] against microbial contamination. Saccharification reaction was performed at $50^{\circ} \mathrm{C}$ and $150 \mathrm{rpm}$ for 2 days. Samples were collected at various intervals and centrifuged at $8,000 \times g$ for $5 \mathrm{~min}$. The supernatants were collected and immediately boiled at $75^{\circ} \mathrm{C}$ for $10 \mathrm{~min}$ to stop the enzyme activity by denaturation. The denatured samples were then cooled, and their reducing sugar content was measured by the DNS (3, 5-dinitrosalicylic acid) method [27]. This amount of generated reducing sugar was multiplied by 0.9 to calculate the saccharification yield (SY). The coefficient 0.9 is the mass ratio of anhydroglucose to its free glucose form [28].

$$
\text { SY }(\%)=\frac{\text { Reducing sugar }(\mathrm{mg}) \times 0.9}{\text { Carbohydrate content in biomass }(\mathrm{mg})} \times 100
$$

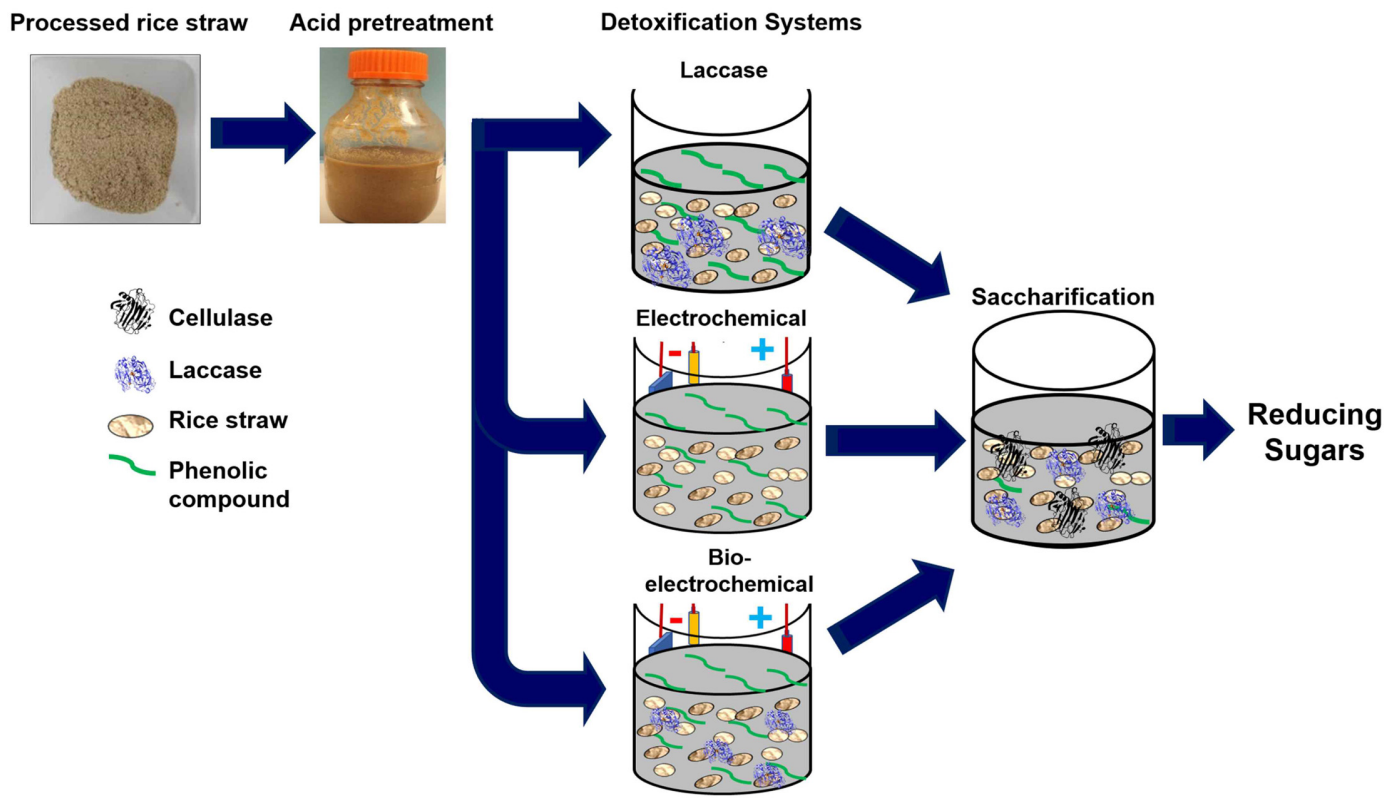

Fig. 1. Schematic representation of the detoxification process employed for treatment of phenolics generated during the pretreatment of rice straw. 


\section{Results and Discussion}

\section{Inhibition of Cellulase by Phenolic Compounds}

Analysis of cellulase activity after incubation with phenolic compounds allowed us to investigate the external factors involved in the decrease of reducing sugar generation from enzymatic hydrolysis of lignocellulosic biomass. Phenolic compounds progressively inhibit most lignocellulosic enzymes [9], and their influence on hydrolytic enzymes has previously been studied [22]. The type and concentration of the phenolic compounds selected in this study were within the range of the effluent amount expected to be generated from the aqueous pre-treatment of wide lignocellulosic materials [22]. To test the influence of external voltage on phenolic degradation, we first used individual phenolic (tannic acid, ferulic acid, 2HBA, gallic acid, coumaric acid, syringic acid, and caffeic acid) compounds with $2 \mathrm{~g} / 1$ and a mixture of phenolic compounds (combination of all phenolics $2 \mathrm{~g} / \mathrm{l}$; tannic acid, ferulic acid,
2HBA, gallic acid, coumaric acid, syringic acid, and caffeic acid), and then proceeded with pre-treated rice straw. The applied voltage level for the removal of phenolic compounds was chosen on the basis of theoretical voltage $[10,17]$. We hypothesized that the phenolic removal rate would be faster by using BEDS than by laccase alone.

The actual number of phenolic compounds and type of inhibitory compounds generated during the lignocellulosic pre-treatment were dependent on the biomass composition, type of pre-treatment, and reaction conditions. BGL was deactivated more than EG and $\mathrm{CBH}$ by the phenolic compounds. Among all the phenolic compounds tested, tannic acid strongly inhibited EG (51\%), CBH (60\%), and BGL (72\%) activities measured by the CMC, $p$-NPC, and $p$ NPG assays, respectively (Fig. 2). The other phenolic compounds exhibited less potent effects than those of tannic acid. After $9 \mathrm{~h}$ of incubation, the phenolic compound mixture with a concentration of $2 \mathrm{~g} / 1$ (combination of all phenolics) exhibited $61.5 \pm 2.1 \%, 74.6 \pm 3.4 \%$, and $82.3 \pm$
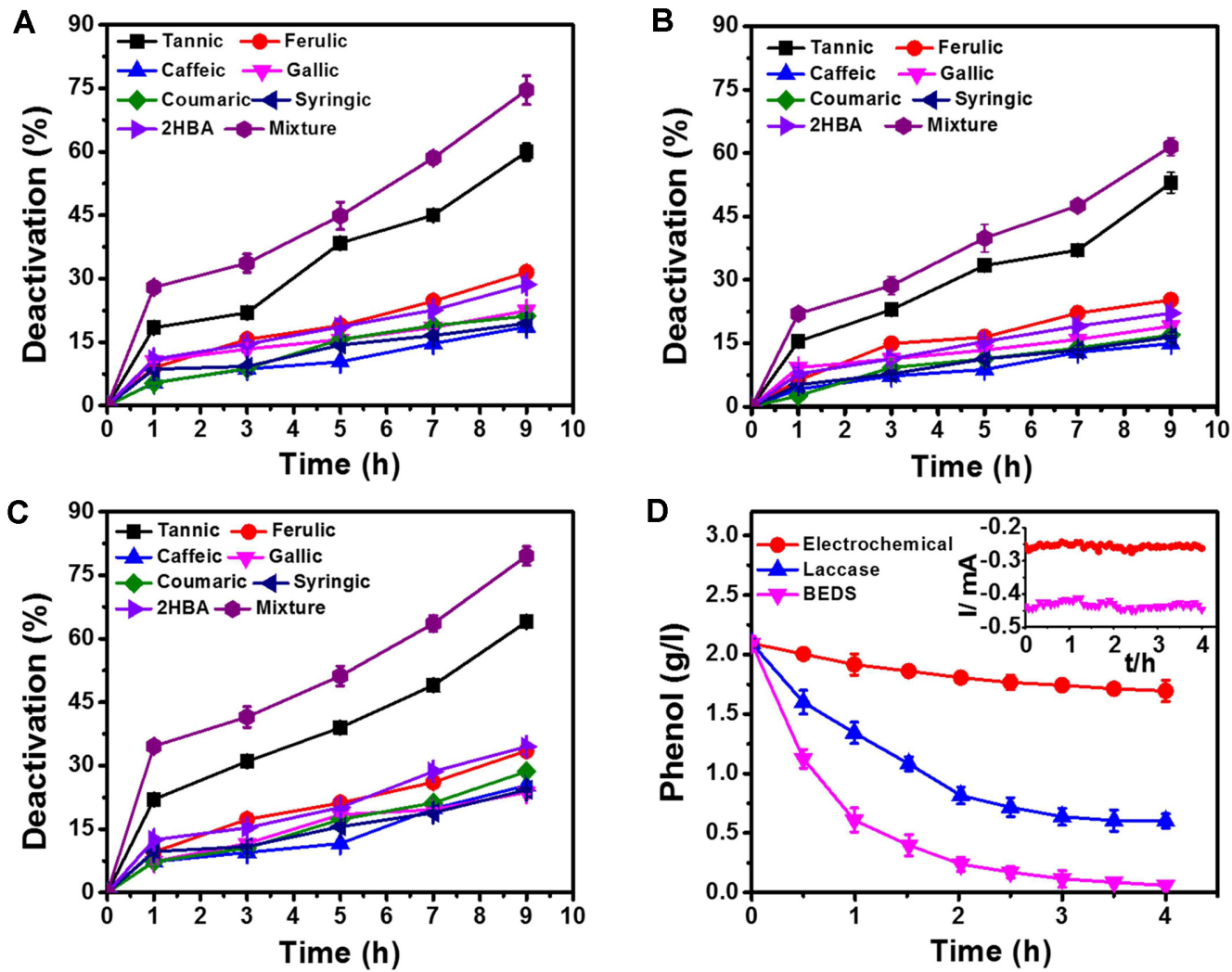

Fig. 2. Deactivation and detoxification of phenols with respect to time.

Individual phenols and mixtures of phenols were used. Deactivation of EG (A), CBH (B), and BGL (C) with various phenolic compounds was analyzed, with CMC, $p$-NPC, and $p$-NPG as the substrate, respectively. (D) Detoxification of the mixture of phenols by various approaches using laccase and an applied voltage of $1.0 \mathrm{~V}$ for the electrochemical system and BEDS. The inset points toward the chronoamperometric current generation are noted with the electrochemical system and BEDS at $1.0 \mathrm{~V}$. 
$4.2 \%$ deactivation of EG, CBH, and BGL, respectively. EG and $\mathrm{CBH}$ followed a similar trend of deactivation by the individual phenolics. The tannic and caffeic acids exhibited the highest and lowest cellulase deactivation, respectively. The influence of the phenolic compounds on EG and $\mathrm{CBH}$ deactivation was noted in the following order:

Phenolic mixture $>$ Tannic acid $>$ Ferulic acid $>$ 2HBA $>$ Gallic acid $>$ Coumaric acid $>$ Syringic acid $>$ Caffeic acid

In the case of BGL, the trend of deactivation by the phenolic compounds was noted as follows:

Phenolic mixture $>$ Tannic acid $>$ 2HBA $>$ Ferulic acid $>$ Coumaric acid $>$ Caffeic acid $>$ Syringic acid $>$ Gallic

The inhibition of cellulase progressively increased.

To detoxify the phenolic compounds, 3 methods were implemented using the mixture of phenolic compounds with a concentration of $2.0 \pm 0.2 \mathrm{~g} / 1$ each (Fig. 2D). The electrochemical, enzymatic (laccase), and BEDS processes were compared for complete degradation of the phenolic compounds. In both the electrochemical and BEDS phenolic oxidation processes, $1.0 \mathrm{~V}$ was used, provided by chronoamperometry. BEDS exhibited a higher $\mathrm{Ph}_{\mathrm{r}}$ than the enzymatic or electrochemical method alone. After $1 \mathrm{~h}$ of detoxification by BEDS, the effluent phenolic concentration, current generation, and phenolic removal percentage were $0.5 \mathrm{~g} / 1,0.43 \mathrm{~mA} / \mathrm{cm}^{2}$, and $75.2 \%$, respectively. The lowest $\mathrm{Ph}_{\mathrm{r}}$ was noted by the electrochemical process with a removal percentage of only $5 \%$, and with an effluent phenol concentration and current generation of $1.9 \mathrm{~g} / 1$ and $0.26 \mathrm{~mA} / \mathrm{cm}^{2}$, respectively. The current generation by BEDS was higher than that by the electrochemical system, possibly due to the presence of the biocatalyst laccase in BEDS [14, 29]. In contrast, the detoxification with laccase alone exhibited a phenolic removal percentage and effluent concentration of $33.0 \%$ and $1.34 \mathrm{~g} / \mathrm{l}$, respectively. The percentage of phenolic compounds removed increased with time during $4 \mathrm{~h}$ of detoxification. At the end of this period, the percentages of the effluent phenolic amount removed by electrochemical, laccase, and BEDS methods were noted to be $15.5 \%, 70.5 \%$, and $97.0 \%$ with corresponding effluent concentrations of $1.69 \mathrm{~g} / 1,0.59 \mathrm{~g} / 1$, and $0.06 \mathrm{~g} / \mathrm{l}$, respectively.

\section{BEDS Detoxification of Pre-Treated Rice Straw Hydrolysate}

Pre-treatment of rice straw generates inhibitory phenolic compounds due to the breakdown of lignin [30]. After the pre-treatment, the rice straw hydrolysate consisted of $0.4 \mathrm{~g} / 1$ of phenolic compounds, which should be removed as they might inhibit the enzymatic activities of cellulases. The efficiency of phenolic compound reduction differed with the type of detoxification process employed (Fig. 3). Among all the detoxification processes, BEDS exhibited the highest reduction in the phenolic compounds (Fig. 3A, Table 1). After $2 \mathrm{~h}$ of operation, an effluent phenolic concentration of $0.08 \mathrm{~g} / 1$ with a removal percentage of $80.5 \%$ was observed. Conversely, the laccase and electrochemical detoxification processes exhibited effluent concentrations of $0.19 \mathrm{~g} / 1$ and $0.27 \mathrm{~g} / 1$, corresponding to $52.5 \%$ and $32.5 \%$ removal percentages, respectively. These values are in line with other studies that used the electrochemical process $[10,17,31]$.

To further test the efficiency of BEDS, the applied voltage was varied during Phr (Fig. 3B). Phenolic removal efficiency varied with the changes in applied voltage. BEDS with $1.5 \mathrm{~V}$ exhibited a higher phenolic compound reduction than with the lower voltages (0.5 V and 1.0 V) (Fig. 3B). Degradation of the phenolic compounds $(0.04 \mathrm{~g} / \mathrm{l})$ was almost complete when $1.5 \mathrm{~V}$ was used. However, BEDS with $0.5 \mathrm{~V}$ and $1.0 \mathrm{~V}$ exhibited an effluent concentration of $0.19 \mathrm{~g} / 1$ and $0.09 \mathrm{~g} / 1$, respectively (Fig. 3C). On the basis of effluent concentration, the removal percentages of the phenolic compounds at $0.5 \mathrm{~V}, 1.0 \mathrm{~V}$, and $1.5 \mathrm{~V}$ were $52.5 \%, 77.5 \%$, and $90.1 \%$, respectively. When $0.5 \mathrm{~V}, 1.0 \mathrm{~V}$, and $1.5 \mathrm{~V}$ were used in the electrochemical system, an effluent phenolic concentration of $0.31 \mathrm{~g} / 1,0.26 \mathrm{~g} / \mathrm{l}$, and $0.22 \mathrm{~g} / 1$ with the removal percentages of $22.5 \%, 35.1 \%$, and $45.2 \%$, respectively, were noted. Further increase in applied voltage beyond $1.5 \mathrm{~V}$ did not exhibit any significant difference in phenol reduction $\left(\mathrm{Ph}_{\mathrm{r}}\right)$. Likewise, oxidative current generation rose with the increase in applied voltage, but faradaic efficiency decreased

Table 1. Effect of applied voltage on the detoxification of phenols and the saccharification yield.

\begin{tabular}{|c|c|c|c|c|c|c|}
\hline \multirow{2}{*}{ Voltage (V) } & \multicolumn{2}{|c|}{ Effluent phenol concentration $(\mathrm{g} / \mathrm{l})$} & \multicolumn{2}{|c|}{ Current (mA) } & \multicolumn{2}{|c|}{ Saccharification yield (\%) } \\
\hline & Electrochemical & BEDS & Electrochemical & BEDS & Electrochemical & BEDS \\
\hline 0.5 & 0.31 & 0.19 & 0.21 & 0.38 & 51 & 61 \\
\hline 1.0 & 0.25 & 0.09 & 0.29 & 0.47 & 56 & 78 \\
\hline 1.5 & 0.22 & 0.04 & 0.34 & 0.59 & 60 & 85 \\
\hline
\end{tabular}



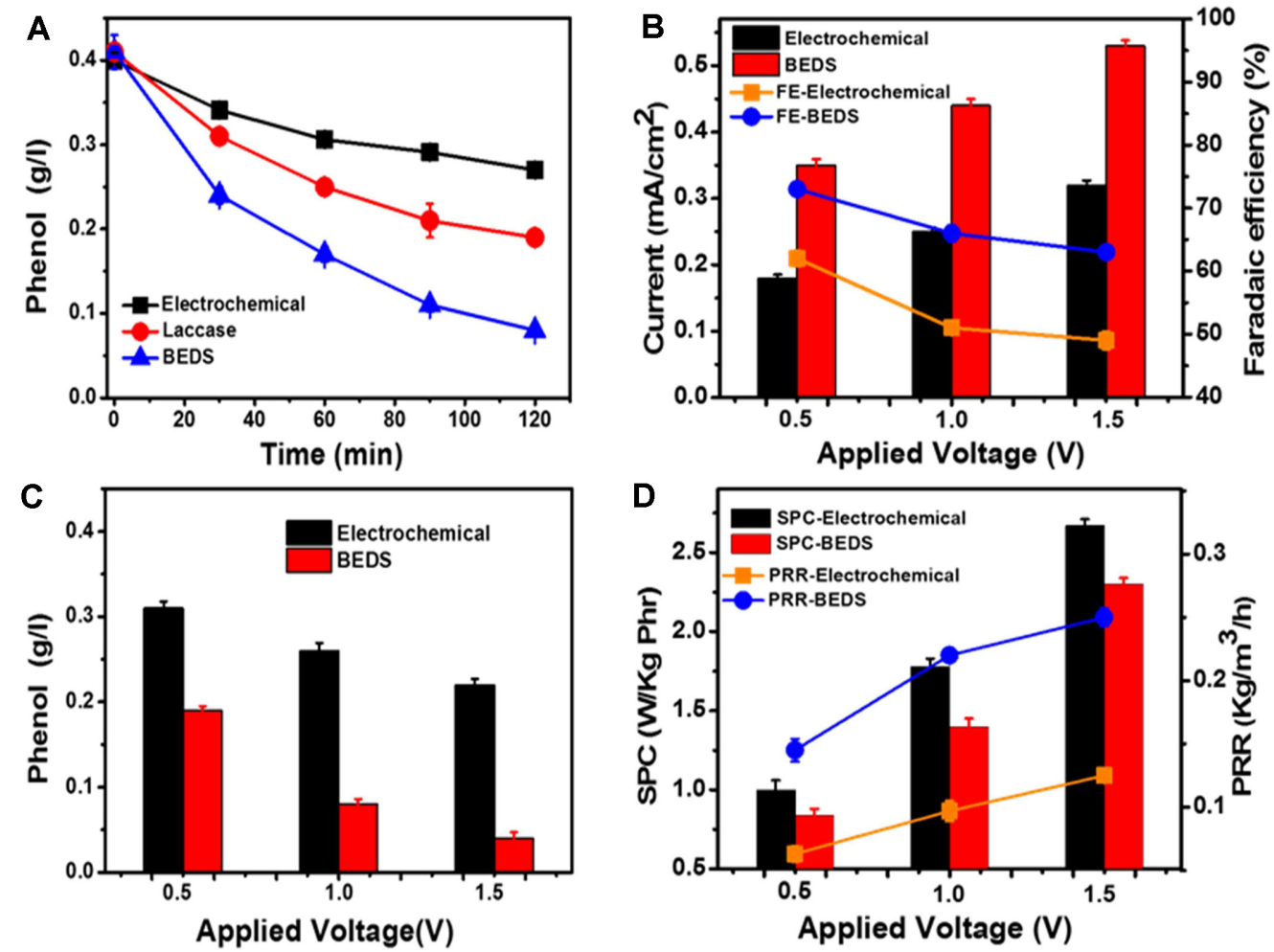

Fig. 3. Detoxification of the phenols generated by pre-treatment of rice straw.

(A) Detoxification of the phenols in pre-treated rice straw by using laccase, the electrochemical system or BEDS at an applied voltage of $1.0 \mathrm{~V}$. (B) Chronoamperometric current generation and faradaic efficiency noted in BEDS and electrochemical system with changes in the applied voltage. (C) Phenol concentration in BEDS and electrochemical system at various applied voltages after $2 \mathrm{~h}$ detoxification. (D) Variation in specific power consumption (SPC) and phenol removal rate (PRR) noted in BEDS and the electrochemical system at different voltages.

[32]. When using BEDS at $0.5 \mathrm{~V}, 1.0 \mathrm{~V}$, and $1.5 \mathrm{~V}$, the oxidative current generation was $0.38 \mathrm{~mA} / \mathrm{cm}^{2}, 0.47 \mathrm{~mA} / \mathrm{cm}^{2}$, and $0.59 \mathrm{~mA} / \mathrm{cm}^{2}$, respectively. The electron utilization was calculated in terms of faradaic efficiency and noted to be $84.2 \%, 76.3 \%$, and $62.4 \%$, respectively. Similar trends in current generation and faradaic efficiency were also noted with the electrochemical system. When $0.5 \mathrm{~V}, 1.0 \mathrm{~V}$, and $1.5 \mathrm{~V}$ were used, the electrochemical system generated $0.21 \mathrm{~mA} / \mathrm{cm}^{2}$, $0.29 \mathrm{~mA} / \mathrm{cm}^{2}$, and $0.34 \mathrm{~mA} / \mathrm{cm}^{2}$ current, respectively. On the basis of $\mathrm{Ph}_{\mathrm{r}}$ and generated electricity, the specific power consumption (SPC) of BEDS and the electrochemical system were calculated at different voltages as previously described [33] (Fig. 3D). A lower SPC was noted with BEDS than with the electrochemical system, possibly due to the presence of laccase in BEDS. The SPC of BEDS at $1.5 \mathrm{~V}$ was $2.2 \mathrm{~W} / \mathrm{Kg} \mathrm{Ph}, 24 \%$ lower than that of the electrochemical system $\left(2.89 \mathrm{~W} / \mathrm{Kg} \mathrm{Ph}_{\mathrm{r}}\right)$. BEDS yielded the maximum phenolic removal rate (PRR) $\left(0.30 \mathrm{Kg} / \mathrm{m}^{3} / \mathrm{h}\right)$ at $1.5 \mathrm{~V}$, followed by $1.0 \mathrm{~V}$ and $0.5 \mathrm{~V}$, with a PRR of $0.23 \mathrm{Kg} / \mathrm{m}^{3} / \mathrm{h}$ and $0.14 \mathrm{Kg} / \mathrm{m}^{3} / \mathrm{h}$, respectively. These values were $52 \%$,
$61 \%$, and $63 \%$ higher than those obtained by the electrochemical system operating at $0.5 \mathrm{~V}, 1.0 \mathrm{~V}$, and $1.5 \mathrm{~V}$, respectively. In contrast, laccase alone exhibited a removal rate of $0.147 \mathrm{Kg} / \mathrm{m}^{3} / \mathrm{h}$. Taken together, these results suggest that BEDS is more effective than electrochemical treatment at reducing phenolic compounds.

\section{Saccharification of Detoxified Rice Straw}

The suitability of BEDS was studied by the reduction of the phenolic compounds produced during the pre-treatment of rice straw. The saccharification procedures were carried out at $50^{\circ} \mathrm{C}, 150 \mathrm{rpm}$, and with a mixture of enzymes (Celluclast, BGL, and laccase) on detoxified and nondetoxified biomass for 2 days. The SY varied with the type of the detoxification process employed (Fig. 4A). The highest SY (85\%, $540 \mathrm{mg} / \mathrm{g}$-substrate) was observed with the detoxified biomass and BEDS at $1.5 \mathrm{~V}$, which was 1.8 times higher than without the detoxification (48\%) (Fig. 4B). Conversely, SYs of the electrochemical system at $1.5 \mathrm{~V}$ and laccase enzymatic process with detoxified biomass were 
A

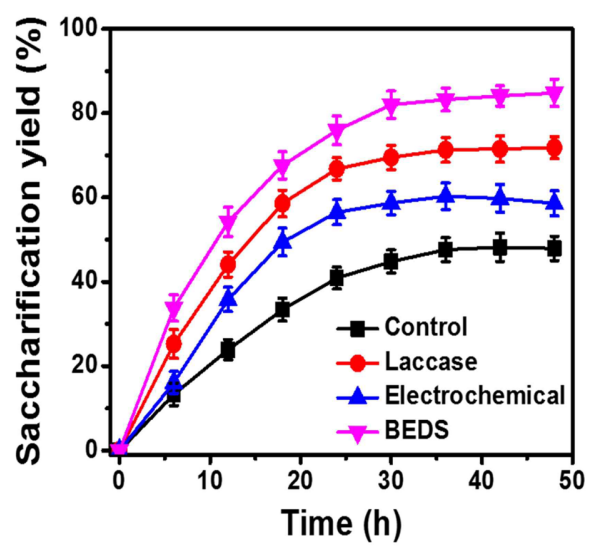

B

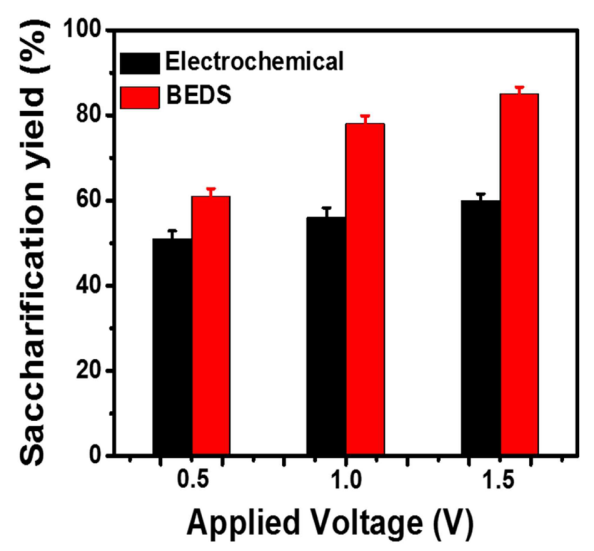

Fig. 4. Sugar yield from saccharification of pre-treated and detoxified rice straw by hydrolysis with cellulases.

(A) Sugar yield by different detoxification strategies during saccharification. The control was performed without any detoxification. (B) The disparity in the yield was noted when detoxified rice straw was used at different voltages with BEDS and the electrochemical system.

$60 \%(412 \mathrm{mg} / \mathrm{g})$ and $71 \%(472 \mathrm{mg} / \mathrm{g})$, respectively. The variations in the applied voltage led to different effluent phenolic concentrations, and hence, a disparity in SY was noted. The SY values of BEDS-treated biomass at $0.5 \mathrm{~V}, 1.0 \mathrm{~V}$, and $1.5 \mathrm{~V}$ were $61 \%, 78 \%$, and $85 \%$, respectively. Likewise, the electrochemically treated biomass at $0.5 \mathrm{~V}, 1.0 \mathrm{~V}$, and $1.5 \mathrm{~V}$ exhibited SY values of $51 \%, 56 \%$, and $60 \%$, respectively. This observation suggests that BEDS is effective in both detoxification and saccharification of biomass. To our knowledge, this is the first report to employ the BEDS system for detoxification of pre-treated biomass for reduction of phenolic compounds. The decrease in the operational costs with the use of BEDS involving crude laccase needs to be evaluated.

To increase the efficiency of enzymatic hydrolysis of lignocellulosic biomass, inhibition and deactivation of the enzymes should be minimized. Phenolics are known to be the major deactivators of cellulolytic enzymes [34-38]. In this study, tannic acid strongly deactivated all the cellulases tested [39, 40]. BEDS effectively removed the phenolics generated during the pre-treatment of lignocellulosic biomass, thereby enhancing the sugar yield. BEDS with $1.5 \mathrm{~V}$ removed $90 \%$ of the phenols at an accelerated removal rate of $0.25 \mathrm{Kg} / \mathrm{m}^{3} / \mathrm{h}$ and SPC of $2.2 \mathrm{~W} / \mathrm{Kg} \mathrm{Ph}$. The energy consumption of BEDS was found to be less than that of the electrochemical system. BEDS exhibited a higher removal rate of phenolics than the other methods tested. These results also indicate that BEDS can save time and decrease chemical usage during the detoxification process. However, further studies are needed to evaluate the energy/price comparison between BEDS and the laccase detoxification process.

\section{Acknowledgment}

This research was supported by the Basic Science Research Program through the National Research Foundation of Korea (NRF) funded by the Ministry of Education, Science and Technology (NRF-2019R1C1C1009766, NRF-2019H1D 3A2A01060226, 2019R1F1A1063131, 2013M3A6A8073184). This research was supported by 2018 KU Brain Pool of Konkuk University.

\section{Conflict of Interest}

The authors have no financial conflicts of interest to declare.

\section{References}

1. Singh RK, Singh R, Sivakumar D, Kondaveeti S, Kim T, Li J, et al. 2018. Insights into cell-Free conversion of $\mathrm{CO}_{2}$ to chemicals by a multienzyme cascade reaction. ACS Catal. 12: 11085-11093.

2. Jin W, Lin H, Gao H, Guo Z, Li J, Xu Q, et al. 2019. N-AcylHomoserine lactone quorum sensing switch from acidogenesis to solventogenesis during the fermentation process in serratia marcescens MG1. J. Microbiol. Biotechnol. 29: 596-606.

3. Otari S, Pawar S, Patel SK, Singh RK, Kim S-Y, Lee JH, et al. 2017. Canna edulis leaf extract-mediated preparation of stabilized silver nanoparticles: characterization, antimicrobial 
activity, and toxicity studies. J. Microbiol. Biotechnol. 27: 731738.

4. Guo Z, Zhao X, He Y, Yang T, Gao H, Li G, et al. 2017. Efficient (3R)-acetoin production from meso-2, 3-butanediol using a new whole-cell biocatalyst with co-expression of meso-2, 3-butanediol dehydrogenase, NADH oxidase, and Vitreoscilla hemoglobin. J. Microbiol. Biotechnol. 27: 92-100.

5. Zhu S, Huang W, Huang W, Wang K, Chen Q, Wu Y. 2015. Pretreatment of rice straw for ethanol production by a twostep process using dilute sulfuric acid and sulfomethylation reagent. Appl. Energy 154: 190-196.

6. Karimi K, Emtiazi G, Taherzadeh MJ. 2006. Ethanol production from dilute-acid pretreated rice straw by simultaneous saccharification and fermentation with Mucor indicus, Rhizopus oryzae, and Saccharomyces cerevisiae. Enzyme Microb. Technol. 40: 138-144.

7. Kumar A, Patel SK, Mardan B, Pagolu R, Lestari R, Jeong S$\mathrm{H}$, et al. 2018. Immobilization of xylanase using a proteininorganic hybrid system. J. Microbiol. Biotechnol. 28: 638-644.

8. Shobana S, Kumar G, Bakonyi P, Saratale GD, Al-Muhtaseb $\mathrm{AaH}$, Nemestóthy N, et al. 2017. A review on the biomass pretreatment and inhibitor removal methods as key-steps towards efficient macroalgae-based biohydrogen production. Bioresour. Technol. 244: 1341-1348.

9. Ximenes E, Kim Y, Mosier N, Dien B, Ladisch M. 2011. Deactivation of cellulases by phenols. Enzyme Microb. Technol. 48: 54-60.

10. Lee KM, Min K, Choi O, Kim K-Y, Woo HM, Kim Y, et al. 2015. Electrochemical detoxification of phenolic compounds in lignocellulosic hydrolysate for Clostridium fermentation. Bioresour. Technol. 187: 228-234.

11. Moreno AD, Ibarra D, Alvira P, Tomás-Pejó E, Ballesteros M. 2015. A review of biological delignification and detoxification methods for lignocellulosic bioethanol production. Crit. Rev. Biotechnol. 35: 342-354.

12. Jönsson LJ, Alriksson B, Nilvebrant N-O. 2013. Bioconversion of lignocellulose: inhibitors and detoxification. Biotechnol. Biofuels 6: 16.

13. Moreno AD, Ibarra D, Fernández JL, Ballesteros M. 2012. Different laccase detoxification strategies for ethanol production from lignocellulosic biomass by the thermotolerant yeast Kluyveromyces marxianus CECT 10875. Bioresour. Technol. 106: 101-109.

14. Fillat Ú, Ibarra D, Eugenio ME, Moreno AD, Tomás-Pejó E, Martín-Sampedro R. 2017. Laccases as a potential tool for the efficient conversion of lignocellulosic biomass: a review. Fermentation 3(2): 17.

15. Kalyani D, Tiwari MK, Li J, Kim SC, Kalia VC, Kang YC, et al. 2015. A highly efficient recombinant laccase from the yeast Yarrowia lipolytica and Its application in the hydrolysis of biomass. PLoS One 10: e0120156.

16. Patel SKS, Choi SH, Kang YC, Lee J-K. 2016. Large-scale aerosol-assisted synthesis of biofriendly $\mathrm{Fe}_{2} \mathrm{O}_{3}$ yolk-shell particles: a promising support for enzyme immobilization. Nanoscale 8: 6728-6738.

17. Sharifian H, Kirk DW. 1986. Electrochemical oxidation of phenol. J. Electrochem. Soc. 133: 921-924.

18. Enache TA, Oliveira-Brett AM. 2011. Phenol and parasubstituted phenols electrochemical oxidation pathways. J. Electroanal. Chem. 655: 9-16.

19. Kumar V, Patel SKS, Gupta RK, Otari SV, Gao H, Lee J-K, et al. 2019. Enhanced saccharification and fermentation of rice straw by reducing the $\mathrm{c}$ oncentration of phenolic compounds using an immobilized enzyme cocktail. Biotechnol. J. 14(6): e1800468.

20. Bradford MM. 1976. A rapid and sensitive method for the quantitation of microgram quantities of protein utilizing the principle of protein-dye binding. Anal. Biochem. 72: 248-254.

21. Dhiman SS, Haw J-R, Kalyani D, Kalia VC, Kang YC, Lee J-K. 2015. Simultaneous pretreatment and saccharification: Green technology for enhanced sugar yields from biomass using a fungal consortium. Bioresour. Technol. 179: 50-57.

22. Ximenes E, Kim Y, Mosier N, Dien B, Ladisch M. 2010. Inhibition of cellulases by phenols. Enzyme Microb. Technol. 46: 170-176.

23. Singh RK, Tiwari MK, Singh R, Lee J-K. 2013. From protein engineering to immobilization: promising strategies for the upgrade of industrial enzymes. Int. J. Mol. Sci. 14: 1232-1277.

24. Shin K, Kim YH, Jeya M, Lee J-K, Kim Y-S. 2010. Purification and characterization of a thermostable cellobiohydrolase from Fomitopsis pinicola. J. Microbiol. Biotechnol. 20: 1681-1688.

25. Jeya M, Lee J-K. 2013. Optimization of $\beta$-glucosidase production by a strain of Stereum hirsutum and its application in enzymatic saccharification. J. Microbiol. Biotechnol. 23: 351356.

26. Lee KM, Kalyani D, Tiwari MK, Kim T-S, Dhiman SS, Lee J-K, et al. 2012. Enhanced enzymatic hydrolysis of rice straw by removal of phenolic compounds using a novel laccase from yeast Yarrowia lipolytica. Bioresour. Technol. 123: 636-645.

27. Miller GL. 1959. Use of dinitrosalicylic acid reagent for determination of reducing sugar. Anal. Chem. 31: 426-428.

28. Jin S, Chen H. 2006. Structural properties and enzymatic hydrolysis of rice straw. Process Biochem. 41: 1261-1264.

29. Shleev S, Jarosz-Wilkolazka A, Khalunina A, Morozova O, Yaropolov A, Ruzgas T, et al. 2005. Direct electron transfer reactions of laccases from different origins on carbon electrodes. Bioelectrochemistry 67: 115-124.

30. Borole AP, Mielenz JR, Vishnivetskaya TA, Hamilton CY. 2009. Controlling accumulation of fermentation inhibitors in biorefinery recycle water using microbial fuel cells. Biotechnol. Biofuels 2: 7.

31. Chu YY, Qian Y, Wang WJ, Deng XL. 2012. A dual-cathode electro-Fenton oxidation coupled with anodic oxidation system used for 4-nitrophenol degradation. J. Hazard. Mater. 199-200: 179-185. 
32. Kuk SK, Ham Y, Gopinath K, Boonmongkolras P, Lee Y, Lee YW, et al. 2019. Continuous 3D Titanium Nitride Nanoshell Structure for Solar-Driven Unbiased Biocatalytic $\mathrm{CO}_{2}$ Reduction. Adv. Energy Mater. 9: 1900029.

33. Kondaveeti S, Abu-Reesh IM, Mohanakrishna G, Pant D, He Z. 2019. Utilization of residual organics of Labaneh whey for renewable energy generation through bioelectrochemical processes: Strategies for enhanced substrate conversion and energy generation. Bioresour. Technol. 286: 121409.

34. Lee N-K, Paik H-D. 2017. Bioconversion using lactic acid bacteria: ginsenosides, GABA, and phenolic compounds. J. Microbiol. Biotechnol. 27: 869-877.

35. Dahili LA, Nagy E, Feczko T. 2017. 2, 4-Dichlorophenol enzymatic removal and its kinetic study using horseradish peroxidase crosslinked to nano spray-dried poly (lactic-coglycolic acid) fine particles. J. Microbiol. Biotechnol. 27: 768774.

36. Lee J-S, Hong S-K, Lee C-R, Nam S-W, Jeon S-J, Kim Y-H. 2019. Production of Ethanol from Agarose by Unified
Enzymatic Saccharification and Fermentation in Recombinant Yeast. J. Microbiol. Biotechnol. 29: 625-632.

37. Sunwoo IY, Nguyen TH, Sukwong P, Jeong G-T, Kim S-K. 2018. Enhancement of ethanol production via hyper thermal acid hydrolysis and co-fermentation using waste seaweed from Gwangalli Beach, Busan, Korea. J. Microbiol. Biotechnol. 28: 401-408.

38. Lee W-H, Jin Y-S. 2017. Evaluation of ethanol production activity by engineered Saccharomyces cerevisiae fermenting cellobiose through the phosphorolytic pathway in simultaneous saccharification and fermentation of cellulose. J. Microbiol. Biotechnol. 27: 1649-1656.

39. Zou Z, Zhao Y, Zhang T, Xu J, He A, Deng Y. 2018. Efficient isolation and characterization of a cellulase hyperproducing mutant strain of Trichoderma reesei. J. Microbiol. Biotechnol. 28: 1473-1481.

40. Yang F, Gong Y, Liu G, Zhao S, Wang J. 2015. Enhancing cellulase production in thermophilic fungus Myceliophthora thermophila ATCC42464 by RNA interference of cre1 gene expression. J. Microbiol. Biotechnol. 25: 1101-1107. 